\title{
Determining The Nutrition of Patient Based on Food Packaging Product Using Fuzzy C Means Algorithm
}

\author{
Sri Winiarti \\ Informatics Department \\ Universitas Ahmad Dahlan \\ Yogyakarta, Indonesia \\ sri.winiarti@tif.uad.ac.id
}

\author{
Sri Kusumadewi \\ Informatics Department \\ Universitas Islam Indonesia \\ Yogyakarta, Indonesia \\ ccie@fti.uii.ac.id
}

\author{
Izzati Muhimmah \\ Informatics Department \\ Universitas Islam Indonesia \\ Yogyakarta, Indonesia \\ izzati@uii.ac.id
}

\author{
Herman Yuliansyah \\ Informatics Department \\ Universitas Ahmad Dahlan \\ Yogyakarta, Indonesia \\ herman.yuliansyah@tif.uad.ac.id
}

\begin{abstract}
The main idea in this research is the utilization of Fuzzy C Means (FCM) method as the determination of patient's nutritional status, which is implemented, in mobile application. Parameters used to cluster nutritional status are height, weight and age. The result of the decision will give 3 clusters on nutritional status is good nutrition, malnutrition and better nutrition. Mobile apps are used as a reminder of the nutritional value or ingredients contained in the packaging of food products while consuming food. The result of system testing for application of FCM algorithm in this mobile application obtained validation of $80 \%$.
\end{abstract}

Keywords-Fuzzy C mean, Nutrition Patients, Food Product.

\section{INTRODUCTION}

GMO (Genetically Modified Organisms) is an organization that controls the detection of food products commercialization by strict regulation [1]. This means that every biotech company that wants to bring their products in the market need to submit a file to the authorization/ deregulation. Moreover, in the European Union (EU), for example, biotech firms need to provide food and conventional counterpart as well as a reliable method of detection / quantification (Commission Regulation EC / 641/2004). Currently, in the European Union "Golden Standard" is implemented to detect this by using the qPCR detection method. The European Union Reference Laboratory ingredients Food and Feed (EU-RL GMFF) validate this through the ring test methods with the help of the National Reference Laboratories (NRL). If adhered methods with the criteria set by the European Network of GMO Laboratories (European Network of GMO laboratories [ENGL], 2008)[2], was made available to the public (Http://gmocrl.jrc.ec.europa.eu/). Furthermore, it can be implemented by GMO detection laboratories [2] when food product follows the rules, it could be able to reduce the cases of the patient's disease that caused due to dietary factors [3].

In Indonesia, there were many cases where patients returned for treatment because of the relapse of the disease due to food intake. Although the government has tightened the supervision related to food products in the regulation of the Minister of Health No. 27 of 2013, they still found products that do not follow these rules in producing food. Thus the regulations need to be implemented in other ways to reduce

This research is supported by Ministry of Research, Technology and Higher Education in the research scheme Higher Education Research Cooperation (Penelitian Kerjasama Perguruan Tinggi/PEKERTI) grant number No: 011/HB-LIT/III/2016 on 15 March 2016 this risk. One way is by utilizing and optimizing the technology of the gadget owned by the patient. Technology that can be used easily by the community is the Android system.

This research will build a system that can determine toddler nutrition by using Fuzzy C-Means (FCM) method based on the barcode from the product packaging. FCM method in this system help classify the nutritional status of children based on the value of the nutrients needed by considering several indicators such as age, height, and weight. This system wills analyzes the nutrition that contained in the product packaging that needed by the toddlers according some indicators such as age, height, weight. Based on the survey results of the initial stage, most of parents who have a smartphone make it possible to use the system any times.

This research uses the FCM algorithm to determine the nutritional value. This is because Fuzzy-clustering method has unsupervised robust data analysis and model construction. In many situations, fuzzy clustering is more natural than hard clustering. Objects on the boundaries between several classes are not forced to fully belong to one of the classes, but rather are assigned membership degrees between 0 and 1 Indicating Reviews their partial membership. Fuzzy c-means algorithm is most Widely used. Fuzzy c-means clustering was first Reported in the literature for a special case $(\mathrm{m}=2)$ by Joe Dunn in 1974. The general case (for any m greater than 1) was developed by Jim Bezdek in his $\mathrm{PhD}$ thesis at Cornell University in 1973. Bezdek can improve it in 1981. The FCM employs fuzzy partitioning the data such that a point can belong to all groups with different grades of membership between 0 and 1 [4].

\section{LITERATURE REVIEW}

\section{A. Related Work}

Joshua M. Krbez, Adnan Shaout, has done one of the studies that have evaluated the application of a fuzzy method for nutrients. The proposals of this paper is a fuzzy logic system journaling diet based on the premise that food intake is a control system. The proposed system is described and implemented. Two methods for nutritional feedback, fuzzy and the other one crisp, are Compared. A comparison is made between the usefulness of fuzzy and crisp diet of data from a user's perspective [5]. 
Other study has already used mobile applications to provide health information in determining the nutrients have been studied by Debi Adriyendi and Syahputra [6]. The purpose of this paper is using the Body Mass Index (BMI) to predicting nutrition status. Caloric needs are an indicator used to determine BMI for men and women. Calorie requirement is used to determine of the needs of Vitamins, Fat, Protein, Carbohydrate and Minerals. This research is implemented in the form of mobile application. The main contribution is to use BMI as the easy, fast and simple to use and can be used to determine the individual nutrition status. The new result is the prediction of the nutrition status of the individual by using BMI and implemented to the cell phone. It is known that an application can yield the rational decision in predicting the nutrition needs.

Maiyaporn Phanich et al. proposed Food Recommendation System (FRS) by using food clustering analysis for diabetic patients [7]. RFS will recommend the proper substituted foods in the context of nutrition and food characteristic. Maiyaporn Phanich et al. used Self-Organizing Map (SOM) and K-mean to clustering food analysis.

Other literature review was also conducted through the books that are relevant to the topic of health information systems and clinical decision support systems that support this research plan. As Gerald L. Glandon, Detlef H SmaltzDonna J.Slovensky, said in his book "Information system for healthcare management, 8Edition, Health Administration Press" [3]. This book gives the reader a comprehensive knowledge needed to understand the health information technology (HIT) and to hone skills in the management of HIT. The book recommends that leaders can demonstrate a basic awareness or competency, including hardware, software, and communications systems; operational, management, and clinical applications; and the selection, implementation, and assessment. In another book written by Karen A. Wager, Frances Wickham Lee, John P. Glaser "Managing Health Care Information Systems: A Practical Approach for Health Care Executives" [8]. In this book give us knowledge of how to organize a health information system for executives in the clinic - health clinics, so that the data held on the transaction property patients become valuable for management.

Based on previous studies, related to the implementation of management concepts for health information systems for health clinics in the form of a notification application for patients with post-hospitalization, to control the consumption of food [9][10].

So in this study will develop the software for the determination of nutrients patients with Fuzzy C-Means (FCM). FCM method in this software classifies nutritional status based on the value of the nutrients needed by considering several indicators such as age, height, and weight. The software will be developed in the form of a mobile-based software. The software will use the bar code from the packaging of food products to determine recommendations related to consumption and nutritional status.

\section{B. Fuzzy C Means}

Fuzzy C-Means (FCM) is a technique for data clustering where each data in a cluster is determined by the value of membership. Jim Bezdek has introduced this technique in 1981 [11].

The basic concept of FCM is to mark the average location for each cluster as the center cluster. In the first condition, the cluster center is still not accurate. Each data has a membership level for each cluster. By repairing the cluster center and membership value of each data repeatedly, it will be seen that the cluster center will move to the right location[4]. FCM algorithm [4]:

1. Input the data into cluster $\mathrm{x}$, in the form of matrix $\mathrm{n} \times \mathrm{m}$ $\mathrm{n}=$ number of samples of data

$\mathrm{m}=$ attribute of each data

$\mathrm{Xij}=$ sample data to-i $(\mathrm{i}=1,2, \ldots, n)$, attribute $\mathrm{j}(\mathrm{j}=$ $1,2, \ldots, \mathrm{m})$.

$$
\mathrm{X}=\left[\begin{array}{ccc}
x_{11} & \cdots & x_{1 m} \\
\vdots & \ddots & \vdots \\
x_{n 1} & \cdots & x_{n m}
\end{array}\right]
$$

2. Determine:

The number of clusters $=\mathrm{c}$;

Rank $=\mathrm{w}$;

Maximum iterations $=$ MaxIter;

Least Expected Error $=\xi$;

Initial Objective function $=0$;

Early iterations $=\mathrm{t}=1$;

3. Generating the random numbers $\mu \mathrm{ik}, \mathrm{i}=1,2, \ldots, \mathrm{n} ; \mathrm{k}=$ $1,2, \ldots, \mathrm{c}$; as elements of the matrix U. $\mu$ ik initial partition is the degree of membership that refers to how likely the data could be members into a cluster. Calculates the sum of each column (attribute):

$$
Q_{j}=\sum_{k=1}^{c} \mu_{i k}
$$

Information:

$\mathrm{C}=$ Total Cluster.

$\mathrm{Qj}=$ number of degrees of membership values each column $=1$ with

$\mathrm{i}=1,2, \ldots \mathrm{m}$

$\mathrm{k}=$ attribute to 1

$\mu \mathrm{ik}=$ degree of membership

$\mathrm{Qj}$ is the sum of the values of degrees of membership each column $=1$ to $\mathrm{j}=1,2, \ldots \mathrm{m}$

Calculate:

$$
\mu_{i k}=\frac{\mu_{i k}}{Q_{j}}
$$

4. Calculate the center of the cluster $\mathrm{k}-\mathrm{k}$ : $\mathrm{Kj}$, with $\mathrm{k}=1,2$, $\ldots, \mathrm{c}$; and $\mathrm{j}=1,2, \ldots, \mathrm{m}$ 


$$
\begin{aligned}
& V_{k j}=\frac{\sum_{i=1}^{n}\left(\left(\mu_{i k}\right)^{w} * X_{i j}\right)}{\sum_{i j}^{n}\left(\mu_{i k}\right)^{w}} \\
& \mathrm{~V}=\left[\begin{array}{ccc}
v_{11} & \cdots & v_{1 m} \\
\vdots & \ddots & \vdots \\
v_{c 1} & \cdots & v_{c m}
\end{array}\right]
\end{aligned}
$$

Information:

$\mathrm{Vk}=$ Cluster Center

$\mathrm{n}=$ Total Sample Data

e $=$ Rank

$\mathrm{Xij}=$ sample data to-i $(\mathrm{i}=1,2, \ldots, n)$, attribute $\mathrm{j}$

$$
(\mathrm{j}=1,2, \ldots, \mathrm{m})
$$

5. Calculate the objective function at iteration $=\mathrm{TPT}$ :

$$
P_{t}=\sum_{i=1}^{n} \sum_{k=1}^{c}\left(\left[\sum_{j=1}^{m}\left(x_{i k}-V_{k j}\right)^{2}\right]\left(\mu_{i k}\right)^{w}\right)
$$

Information:

$$
\begin{array}{ll}
\mathrm{Pt} & =\text { Objective Function } \\
\mathrm{c} & =\text { Number of Cluster } \\
\mathrm{n} & =\text { Total Sample Data } \\
\mathrm{m} & =\text { attribute of each data } \\
\mathrm{Vkj} & =\text { Cluster Center } \\
\mathrm{Xij} & =\text { sample data to-i }(\mathrm{i}=1,2, \ldots, \mathrm{n}), \text { attribute } \mathrm{j} \\
(\mathrm{j}=1,2, \ldots, \mathrm{m}) & \\
\mu \mathrm{ik} \quad=\text { degree of membership }
\end{array}
$$

$\mathrm{t}$ is the calculated iteration, if iteration starts from 1 then at the beginning of calculation the value of $t$ is 1 . The iteration will be repeated in accordance with the provisions of the iteration that is running. Calculate the partition matrix change.

6. Calculate the changes of matrix partition:

$$
\mu_{i k}=\frac{\left[\sum_{j=1}^{m}\left(X_{i k}-V_{k j}\right)^{2}\right]^{\frac{-1}{w-1}}}{\sum_{k=1}^{c}\left[\sum_{j=1}^{m}\left(X_{i k}-V_{k j}\right)^{2}\right]^{\frac{-1}{w-1}}}
$$

Information :

$$
\begin{aligned}
& \mu \mathrm{ik} \quad=\text { degree of membership } \\
& \text { Xik }=\text { sample data to-i }(\mathrm{i}=1,2, \ldots, \mathrm{n}), \text { attribute } \mathrm{k} \\
& (\text { with } \mathrm{k}=1,2, \ldots, \mathrm{c}) \\
& \mathrm{Vkj} \quad=\text { Cluster Center } \\
& \mathrm{c} \quad=\text { Number of Cluster } \\
& \mathrm{m} \quad=\text { attribute of each data } \\
& \mathrm{w} \quad=\text { exponent value }
\end{aligned}
$$

This step is to change the parameter values used in the fuzzy c-mean algorithm. The goal is to see the effect of the specified parameter values. In this study the parameters used are height, weight and age.

7. Check the stops condition.

If: $(|\mathrm{Pt}-\mathrm{Pt}-1|<\xi)$ or $(\mathrm{t}>$ maxIter) then stops.If not: $\mathrm{t}$ $=\mathrm{t}+1$, repeat step 4

Iterations will be repeated if certain values or conditions have not been reached. The condition is if: $(|\mathrm{Pt}-\mathrm{Pt}-1|<\xi)$ or ( $\mathrm{t}>$ MaxIter) then stop which $\mathrm{Pt}$ is the center of the iteration cluster to $t$ less than the expected error value or if $\mathrm{t}$ (number of iterations) is greater than Maximum iteration. However, if iteration will be repeated with $t+1$ then it will repeat the 4 th process or count the center of the cluster again.

\section{METHODOLOGY}

The development stage of this research using waterfall method. The waterfall model encompasses activities activities as follows:

\section{A. Analysis}

This analysis stage determines the system needs, such as the functional and non-functional requirements.

- Functional Requirements, It is include the need of authorization, for example user as admin, user as an expert and user as a patient.

- Non-Functional Requirements. Internet connection is needed by users to run this application and to access all related data.

\section{B. Units}

At the design stage of this system is to design the software components. Several phases during the design stage of the system are as follows:

- Flow Algorithm of Decision Making using CMeans Fuzzy method.

- Create a knowledge base. The knowledge base in this system contains the data needed to build the system. The knowledge base contains the knowledge to understanding, formulation, and problem resolution.

- Make a rule base (rule table). In this system the rule base contains rules that will be used to help make a decision.

- Create a business process

- Business process contains a set of structured activities that occur in the system aka constructed and interconnected to solve a problem.

\section{Implementation}

The next step is to implement the system design into source code. It uses android version 2.2 (froyo).

\section{System Testing (Testing)}

To optimize the system that has been built to work well, then the system proceeds to the testing phase. In this stage system will be tested using User Acceptance Test (UAT) and usability testing using System Usability Scale (SUS) [12][13][14]. 


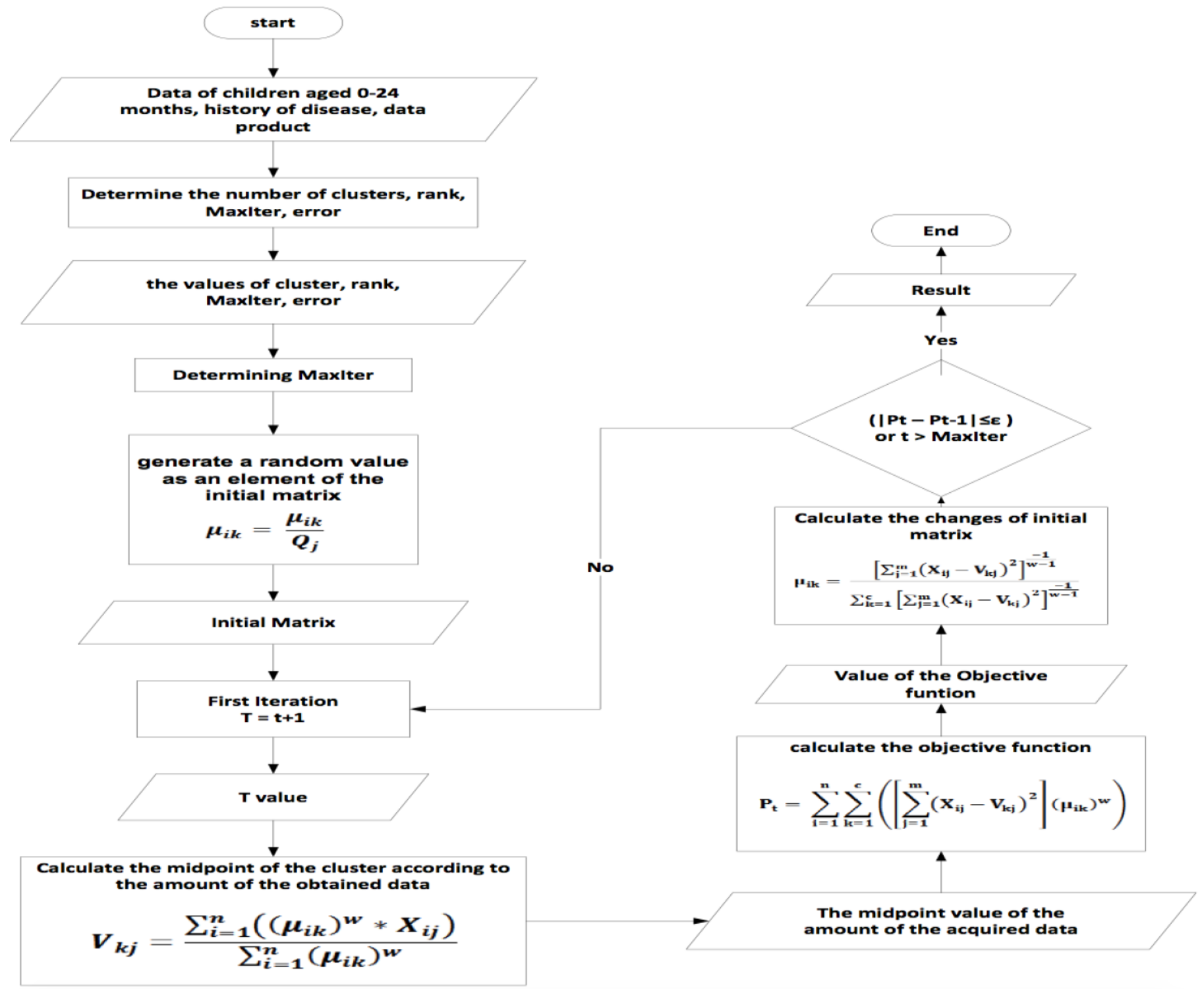

Fig. 1. FLOW OF FCM ALGORITHM

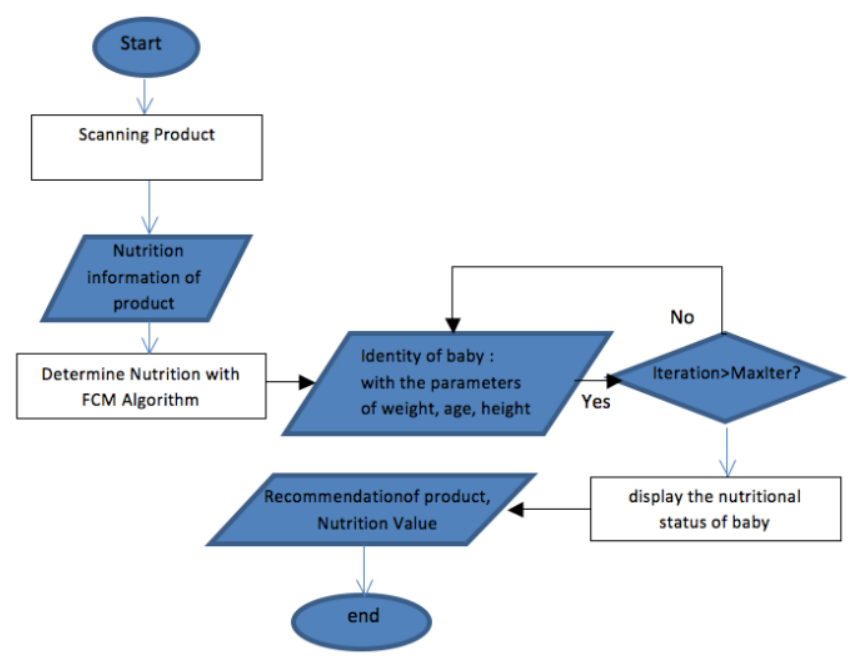

FIG. 2. THE PROCESS FLOW OF THE FUNCTION OF A NUTRITION EXPERT 


\section{RESULT AND DISCUSSION}

The method used is fuzzy C Means (FCM). FCM is a clustering method in which the existence of each data point in a cluster is determined by the degree of membership. The advantage of this method is able to grouping for scattered data irregularly.

The decision to determine the patient's (toddler) nutritional by applying the FCM algorithm. The rule is for each patient's the algorithm Fuzzy C Means (FCM) will calculate data criteria. Figure 1 illustrates the flow of FCM algorithm.

In Figure 1, the data of the patients (infants) entered by the user to determine the nutritional status of patients. This determination process will be recomputed to get a stable value of $\mathrm{T}$, where $\mathrm{T}=\mathrm{t}+1$. If the final value $\mathrm{T}>$ Iteration Maximal value, then the conclusion of patient nutrition status could be made. If it has not reached the maximum iteration, then the initial iteration will be done. This process will be continuing until the maximum iteration conditions are met. FCM algorithm will determine the status of the patient. In this system, there will be three outputs, namely: Malnutrition, Medium nutritional status and good nutritional status. After the patient's nutritional decisions was decided, then the next user can scan the packaging of products to be purchased. Furthermore, the system will give a recommendation whether the users could consume the product or not.

The flowchart of the system can be seen in Figure 2 . Notification system based on the determination of a patient's nutritional product packaging describes the function of the user as parents in using the system. Illustrated in Figure 2, the parents who will buy the product for their children's first will scan the products using Android smartphone. Then system will display the nutrition information on the packaging of products. Furthermore, parents will check the nutritional status of children under five with three input parameters such as weight, height and age.

In Fig. 2, system will provide nutrition status and recommendations related to the products that have been scanned. Recommendations about whether or not these products could be consumed by their children by adjusting the nutritional status of children who have been checked through the system.

By applying the FCM algorithm, the system will give information about children's nutritional status and recommendation on the product. Nutrition Specialist is responsible for all knowledge related to nutrition and patient cases, nutritional value information and product recommendations that match the nutritional status of the patient's information. Patients must login and input the parameters such as weight, height and age in order to use the system. Implementation in mobile applications is presented in Figure 3.

System testing has been conducted on 10 patients represented by parents who have children. Tests conducted with three input parameters, they are Height, Weight and Age, and the results $80 \%$ are valid. Table 5.3 is a form of presentation of data on test results from 10 patients. Parents will input the data via the system by adjusting the toddler real facts. Tests performed on the parents in supermarkets Pamela 3 Jogjakarta when they want to buy the children's product.

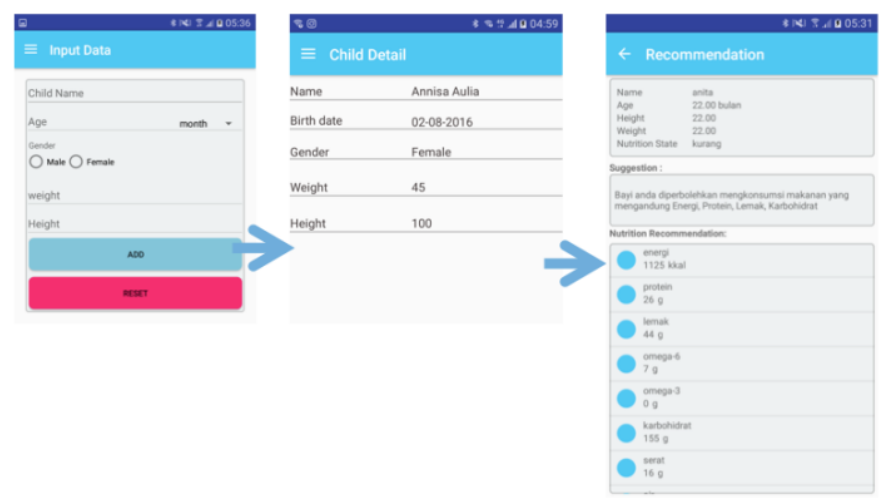

FIG. 3. IMPLEMENTATION OF THE NOTIFICATION SYSTEM OF NUTRITIONAL VALUE WITH ANDROID

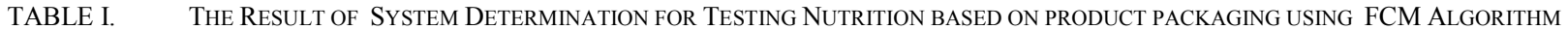

\begin{tabular}{|c|c|c|c|c|c|c|c|c|c|}
\hline \multirow{2}{*}{ Cases } & \multicolumn{3}{|c|}{ Manual Test } & \multirow{2}{*}{ Result } & \multicolumn{3}{|c|}{ System Test } & \multirow{2}{*}{ Result } & \multirow{2}{*}{ Information } \\
\hline & Height & Weight & Age (month) & & Height & Weight & Age (month) & & \\
\hline Case 1 & 73 & 9 & 14 & Malnutrition & 73 & 9 & 14 & Malnutrition & Valid \\
\hline Case 2 & 78 & 8.5 & 10 & Malnutrition & 78 & 8.5 & 10 & Malnutrition & Valid \\
\hline Case 3 & 101 & 15 & 43 & Good nutrition & 101 & 15 & 43 & Better nutrition & Unvalid \\
\hline Case 4 & 65 & 8.5 & 12 & Malnutrition & 65 & 8.5 & 12 & Malnutrition & Valid \\
\hline Case 5 & 113 & 19 & 72 & Malnutrition & 113 & 19 & 72 & Malnutrition & Valid \\
\hline Case 6 & 70 & 7 & 10 & Malnutrition & 70 & 7 & 10 & Malnutrition & Valid \\
\hline Case 7 & 81.5 & 11 & 19 & Malnutrition & 81.5 & 11 & 19 & Malnutrition & Valid \\
\hline Case 8 & 95 & 13.6 & 44 & Malnutrition & 95 & 13.6 & 44 & Better nutrition & Unvalid \\
\hline Case 9 & 90 & 11.5 & 48 & Better nutrition & 90 & 11.5 & 48 & Better nutrition & Valid \\
\hline Case 10 & 97.5 & 16.7 & 37 & Good Nutrition & 97.5 & 16.7 & 37 & Good Nutrition & Valid \\
\hline
\end{tabular}

System testing is done by changing inputs in some inputs on the FCM process. The input, to be changed, is the maximum iteration, rank, smallest error, objective function and initial iteration. Then for the number of clusters will not be changed. The number of clusters is the assessment range of the clustering results. Range assessment is good nutrition, malnutrition and better nutrition. Therefore the number of clusters is set by 3 clusters. The purpose of this test is to know the performance of FCM algorithm in doing ranking. Such performance is judged by the degree of success of the 
algorithm in rankings compared to patient data obtained and calculated manually in the corresponding year from the data source. From the test results with 10 data, then obtained cluster of different rank values, so that the outputs are different. In Table I, case data 3 and case 8 were tested with input of rank 1 , the result of data obtained with the built system was not in accordance with the data source acquisition results, that is with the $80 \%$ validation rate.

Testing with maximum iteration obtained results that vary each outpunya. Maximum of iteration 1 obtained by category in 3rd and 8th cases in table $\mathrm{I}$ is invalid because the number of iteration is too small so the result is not right because the cluster center has not moved to the right position. Because iteration will stop if the value of the objective function during iteration to $\mathrm{t}$ and the objective function during the previous iteration $(|\mathrm{Pt}-\mathrm{Pt}-1|<\xi)$ the difference is smaller with the smallest error expected.

\section{CONCLUSION}

The conclusions of this research are that the algorithm FCM can be applied in determining a patient's nutritional. System testing has been done using FCM algorithm, the result is that $80 \%$ of the test is worth valid for the determination of nutrients for infants. The value of patient nutrition status can be known, the result can be used to determine the product packaging can be consumed by patients or not. There are 2 outputs from the system, consist of;

1. Patient's nutritional group can be made into three clusters, namely: better nutrition, good nutrition and malnutrition.

2. Provide product recommendations, that are; be consumed, not consumed and should be consumed with a pre-cautions.

\section{ACKNOWLEDGMENT}

The authors would like to thank the anonymous reviewers for their comments and suggestions that helped to improve the quality and presentation of this paper and Nur Rachmaliany, Lalu Hilmi Fadli for her help to contribution as student's researcher in this paper.

\section{REFERENCES}

[1] Gruère, Guillaume P. \& Rao, S.R, A Review of International Labeling Policies of Genetically Modified Food to Evaluate India's Proposed Rule, The Journal Agrobiotechnology Management and Economic,volume 10, number 1, article 6,

[2] European Network of GMO Laboratories. (2017, Apr 10). ENGL and EURL - Two European partners in GMO detection [Online]. Available: http://gmo-crl.jrc.ec.europa.eu/ENGL/ENGL.

[3] Gerald L. Glandon, Detlef H SmaltzDonna J. Slovensky, 2014, Information system for healthcare management, 8Edition, Helth Administration Press.

[4] R.Suganya, R.Shanthi, 2012, Fuzzy C-Means Algorithm-A Review, International Journal of Scientific and Research Publications, Volume 2, Issue 11, November 20121 ISSN 2250-3153.

[5] Joshua M. Krbez, Adnan Shaout, 2013, Fuzzy Nutrition System, International Journal of Innovative Research in Computer and Communication Engineering (An ISO 3297: 2007 Certified Organization) Vol. 1, Issue 7, September 2013

[6] Adriyendil and Syahputra, D, 2013, Prediction Nutrition Status using Body Mass Index on Mobile Device, International Journal of BioScience and Bio-Technology Vol. 5, No. 1, February,2013

[7] M. Phanich, P. Pholkul, and S. Phimoltares, "Food Recommendation System Using Clustering Analysis for Diabetic Patients," 2010 Int. Conf. Inf. Sci. Appl., pp. 1-8, 2010.

[8] Karen A. Wager, Frances Wickham Lee, John P. Glaser, juli 2014 Managing Health Care Information Systems : A Practical Approach for Health Care Executives

[9] S. Kusumadewi, S. Hartati, "Utilizing Fuzzy Multi-Attributr Decision Making for Group Clinical Decision Making Model,“ in Proc. International Conference on Soft Computing, Intelligent System \& Information Technology Univ Petra Surabaya, pp. 18-24, July. 26-27, 2007.

[10] S. Kusumadewi, S. Hartati, "Sensitivity analysis of multi-attribute decision making methods in clinical group decision support system," in Proc International Conference Intelligent and Advanced Systems (ICIAS) Universiti Technology Petronas Malaysia, pp. 301-304 November 2007.

[11] Bezdek, J. C., Ehrlich, R., \& Full, W. 1984. FCM: The fuzzy c-means clustering algorithm. Computers \& Geosciences, 10(2-3), 191-203.

[12] Grier. R.A, Bangor. A, Kortum.P, Peres. S. C, The System Usability Scale Beyond Standard Usability Testing, SAGE Journal International, Volume 57, Issue 1, 2013

[13] Brooke, J. 1996. SUS-A quick and dirty usability scale. Usability evaluation in industry, 189(194), 4-7.

[14] Martins AI, Rosa AF, Queros A, Silva A, Rocha NP. European Portuguese validation of the system usability scale (SUS). Procedia Computer Sceince. 2015: 293-300 